\title{
Lina Kohen Albukrek'in "Hanuka" Şiirine Bilişsel Şiirbilimsel Bir Yaklaşım
}

FAZILA DERYA AGIŞ̧*

\section{Öz}

Bu çalışmada, bir Sefarad şairi olan Lina Kohen Albukrek'in "Hanuka" başlıklı şiiri Reuven Tsur tarafından geliştirilen bilişsel şiirbilim açısından incelenmiş ve şiirdeki kültürel motiflere açılamalar getirilmiştir. Türk Sefaradları, 1492 yılında Kraliçe Isabella ve Kral Ferdinand'ın emriyle İspanya'dan Katolik olmayı reddettikleri için sınır dışı edilen ve Osmanlı İmparatorluğu tarafından kabul edilen Yahudiler'dir. Dönemin Yahudileri tarafından Orta Çağ İspanyolcasına Türkçe- İbranice kelimelerin de karıştığı Ladino ya da Yahudi İspanyolcası denilen bir dil kullanılır ve bunların birçoğu günümüzde İstanbul ve İzmir'de yaşar. Lina Kohen Albukrek de bir Sefarad'dır.

Anahtar sözcükler: Bilişsel şiirbilim, Türk Sefarad Yahudi Kültürü, antropolojik edebiyat, sosyolojik şiir.

\section{A COGNITIVE POETIC APPROACH TO}

\section{LINA KOHEN ALBUKREK'S POEM “HANUKKAH”}

\begin{abstract}
In this study, Lina Kohen Albukrek's poem "Hanukkah" will be analyzed within the context of the theory of Cognitive Poetics developed by Reuven Tsur, and cultural motifs in the poem will be scrutinized. Turkish Sephardim are the Jews who were accepted by the Ottoman Empire, after they had been expelled from Spain by Queen Isabella and King Ferdinand in 1492 since they had rejected to convert into Catholicism. They use a language called Ladino or Judeo-Spanish into which Turkish and Hebrew words entered. Most of them live in Istanbul and Izmir today. Lina Kohen Albukrek is also a Sephardic.
\end{abstract}

Keywords: Cognitive poetics, Turkish Sephardic Jewish culture, anthropological literature, sociological poetry.

*Ankara Üniversitesi Sosyal Bilimler Enstitüsü İtalyan Dili ve Edebiyatı, deryaagis@gmail.com 


\section{Giriş}

Oiir yazarken şairin çeşitli anlambilimsel,

sesbilimsel ve sözdizimsel birtakım oyunlara

5 başvurması kaçınılmazdır. Bütün bu oyunlar, şairin zihninde yer eden duyguları okuyucusunda da uyandırma çabasının bir sonucudur. Duygular insan zihninde belirirler: insan beyninin sağ kısmı negatif, sol kısmı ise pozitif duyguların oluştuğu yerlerdir (Ratey, 2001: 229).

Bilişsel bilimlerin temel amacı insan zihninde olup biteni araştırmaktır. Dolayısıyla gelişmekte olan disiplinlerarası bilişsel bilimler edebiyatı da içine alır. Sanatçılar sanat ürünlerini tamamlarken çeşitli algı

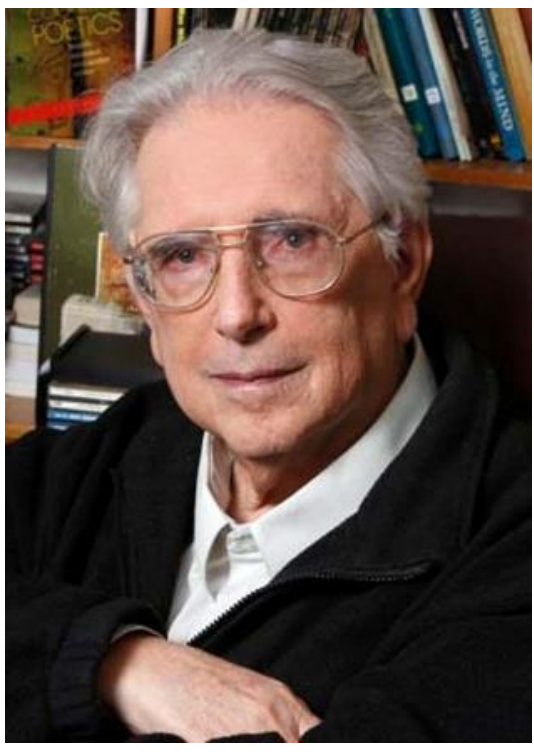

Reuven Tsur organlarını kullanır. Beyine bilgiyi aktaran algı organları arasında gözler, ten, burun ve kulaklar vardır; görme, dokunarak algılama, koklama ve işitme beyinde belirli bölgeleri harekete geçirir (detaylar için Rizzolatti ve Sinigaglia 2008: 4). $\mathrm{Bu}$ somut algı organları vasıtasıyla beyine aktarılan farklı olaylar korku, yardımseverlik gibi çeşitli soyut duygulara yol açarlar (Ratey 2001: 223). Şairlerin de şiirlerinde dile getirdikleri duygularını okuyucuya iletebilmek için bazı dilsel algı oyunlarına başvurması kaçınılmazdır. Şiir okuyucu önünde yazın olması nedeniyle görsel somut bir araçtır. Bu bağlamda İsrailli bilim adamı Reuven Tsur 1992 yılında Toward a Theory of Cognitive Poetics [Bilişsel Şïrbilim Teorisine Doğru] başlıklı kitabını yayımlamıştır. Tsur bu kitabında sinirbilim ile edebiyat arasında disiplinlerarası bir bağ bulunduğunu savunur. Ona göre, şiir bilişsel bilimler ve beyin çalışmaları olarak adlandırılan disiplinlerarası araştırma dallarının bir konusu olabilir. Bir başka tanımla, ruhsal dilbilim açısından edebiyat yazılarının özellikleri incelebilir. Bu nedenle, aynı kitabında Tsur şiirlerde şairin okuyucuda kendi hissettiği soyut duyguları uyandırabilmek için bilişsel algılamaya yönelik bazı şiir üzerinde gözle görülebilen somut dilsel oyunlara başvurduğunu savunur, örneğin belirli bir negatif ya da pozitif duyguyu anlatan bir şair şiirinde belirli kafiyeler kullanır. Ayrıca Tsur (1992)'a göre, bir şiirde tasvir edilen kavramların özellikleri anlambilimsel açıdan şiir yorumlanmasında kelimelerin doğru anlaşılmasını sağlar (bunlara silinme ve çoğaltılma denilir, silinmeler '-', arttırmalar ' + ' işaretleri ile gösterilir (örneğin tavuk [+dişi, -eril, +canll, -cansız]; metaforik kelime kullanımlarında bu özellikler değişebilir). Bununla birlikte, Tsur (1992)'un kuramında, şiirde tasvir edilen ortamın hangi zamana ait olduğu, fiil çekimleri ile ortaya çıkar; buna yersel ve zamansal yakınlık denilir. Bilişsel olarak kavramlar kategorilere ayrılır: örnek olarak, meşe ve çam ağaç üst kategorisinin alt kategorileridir. Bunlar kavramsal 
sınıflamalardır. Bunlara ek olarak, tasvir edilen olaylar bir çerçeve içindeki resim gibi okuyucunun zihninde canlanır. Buna bilişsel çerçevelendirme denilir. Tsur (1992) ruhsal alanlara (şiire hâkim olan baş duyguyu açıklayan nesneler bütünü), sembollere, soyutlamalara ve imalara da şiir yorumlanmasında önem verir. Hepsi birer dilsel oyundur. Bununla birlikte, şair kendisinde bir duygu uyandıran dokunarak, işiterek, koklayarak ve görerek şahit olduğu olayı metaforlar kullanarak tasvir eder. Kısaca, Tsur (1992), bilişsel şiir incelemesinde (a) şiirin sesletim yapısını oluşturan ritimlere ve seslere, (b) anlam birimlerine (anlambilimsel temsiller, bilgi işleme süreçleri, metaforlar, vs.), (c) cümle stili gibi düzenleyici kavramlara, (d) mistik şiir, grotesk şiir gibi şiirin akım yönelimlerine, (e) şiirin insan bilincine karşı yaklaşımlarına ve (f) bilişsel dilbilim kuramına yer verilmesi gerektiğini savunur. Ayrıca Tsur (2002) şiir yapıları yaratmayı ve bu yapıların okuyucu üzerinde şairin düşünceleri ile aynı etkileri yaratabilmesini 'şiirsel yeterlilik' olarak tanımlar.

Tsur (2002), bilişin algı, hafıza, dikkat, problem çözme, dil, düşünce ve hayal gücünü kapsadığını açıkça belirtir ve bilişsel şiirbilimi yaratıcılık ve yenilik açısından birbirini tamamlayan iki unsura bağlar. Bunların ilki anlam karmaşalarına yol açan veya bu karmaşaları çözen bilişsel süreçler ve diğeri şiirin yorumlanabilirliğini sağlayan bilişsel zorunluluklardır (bu zorunluluklar dil oyunlarıdır). Tsur (2002)'un Shelly'in "A Song" [Bir Şarkı] başlıklı şiirini incelemesi örnek olarak gösterilebilir:

\footnotetext{
A widow bird sate mourning for her love (Dul bir kuş aşkı için yas tutmaya doydu)

Upon a wintry bough (Kıştan kalma bir dal üzerinde)

The frozen wind crept on above, (Donuk rüzgâr tepeden emekleyip geçti)

The freezing stream below. (Donan akarsu aşağıda)
}

\footnotetext{
There was no leaf upon the forest bare (Çıplak ormanda hiçbir yaprak yoktu)

No flower upon the ground, (Yerde bir yaprak yoktu,)

And little motion in the air (Ve havada sadece küçük bir kımıldama)

Except the mill-wheel's sound. (Değirmen tekerleğinin dişında.)
}

Tsur (2002)'a göre bu şiir müzikseldir, bu şiirde duygular yoğundur; atmosferi de bu yoğun duygular ile ilintilidir. Tsur (2002) şiir hakkındaki görüşlerinde ilk dizede birbirleriyle bağlantıları olan metaforlar olduğunu belirtir: ona göre, sadece insanların sevgilisi olabilir; sadece insanlar yas tutar ve dul kalır. Bu durumda kuş ve geçmişte kalan “crept on" eylemi (Türkçe olarak "emekleyip geçti") birer metaforik kullanımdır. Rüzgâr bebeğe benzetilmiştir. Şiir bir düzlügün tasviri ile devam eder. Kuş, dal, ağaç, rüzgâr, akarsu, orman, toprak ve değirmen sesi bir çerçeve oluşturur. Üçüncü ve dördüncü dizeler yavaşlama eylemi ile 
ilgilidir: akarsu ve rüzgârın ritimleri yavaştır; buz gibidirler. Beşinci ve altıncı dizeler de bitki örtüsünün yokluğu ile ilgilidir: yaprak ta çiçek te şiirin çerçevesinde yoktur. Enerjisi düşük bu manzara üzüntü duygusunu tasvir eder. Ayrıca beşinci ve altıncı dizelerde [+yoksunluk] ve [-çoşkunluk] anlamları çıkartılır. Şiirde duygusal bir atmosfer tasvir edilmekte ve okuyucuya bu duygular metaforik kelime oyunları ile tattırılmaktadır. Tsur (2002) aslında "dünyayı çevreleyen gazsı sıvı" olan atmosferin de bir sanat eserinde anlatılan duyguyu tanımladığı için bir metafor oluşturduğunu savunur. Son olarak, şiirdeki "little" ("küçük") ile "no" ("hiç") kelimeleri yokluğu vurgular. Tsur (2002)'un bu açıklamaları geçmişte yaşanan

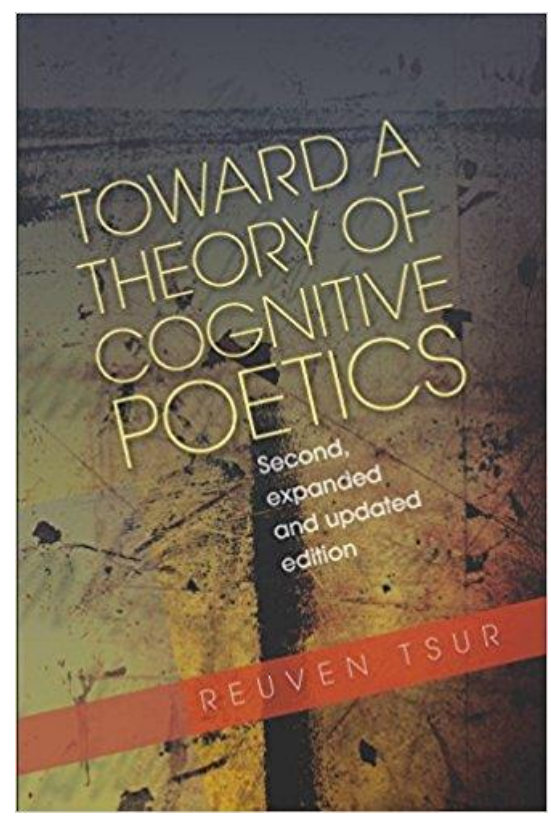

Bilişsel Şiirbilim Teorisine Doğru bir ölüm duygusunun belirli bir çerçeve içine konulmuş resim gibi şiir vasıtasıyla okuyucuya aktarıldığı gösterir. Şiirin okuyucusu görsel, işitsel ve dokunmatik algının beyinde yarattığı duyguları hayalinde kolaylıkla canlandırabilir: anlatılan doğa manzarası görsel, değirmenin sesi işitsel ve rüzgârın soğukluğu tensel algılama ile ilgilidir. Alg1 ve duygular bilişsel psikolojinin konusudur: ikisi de beynin işlevleri ile ilgilidir.

Ayrıca Tsur (2002) psikologların duyguları aşağıdaki kriterler bakımından incelediğini söyler:

1. Bilişsel durum övgüsü,

2. Negatif ve pozitif duygulara bağlı enerji artışı ve düşüşü,

3. Kavramlara ilişkin bilgilerin, kavramların anlamını yitirmesine neden olması ve

4. Böyle bilgilerin zihnin ardında aktif hâlde olmaları.

Şiirlerde de duygular bu dört kategoriye uygun olarak okuyucuya iletilir. Hayal gücü şiirsel anlam yaratmada en etkili güçtür. Tsur (1992 ve 2002)'un verdiği bilgileri Brandt ve Brandt (2005: 121) şiir yorumlarken aşağıda belirtilen dört unsura dikkat edilmesi gerektiği söyleyerek destekler:

1. Dil bilgisi ve telaffuz,

2. Metnin anlambilimsel içeriği (hayal gücü ve anlatım da dâhil),

3. Yazım biçimi ve

4. Bir türün çerçevesinde yorumlanabilir estetik durum.

Tsur (1992)'un şiirin doğru anlaşılabilmesi için gerekli bulduğu okuyucuda etki oluşturmak için kullanılan zihinsel oyunlar olan anlambilimsel silinme ve çoğaltılmaların, yersel ve zamansal devamlılı̆̆ın, şiirde kullanılan isimlerin ait olduğu kavram sınıflarının, 
tasvir edilen olayın sunduğu çerçevenin, ruhsal alanın, sembollerin, soyutlamaların, imaların ve kafiyelerin Lina Kohen Albukrek'in Hanuka başlıklı şiirindeki yerini incelersek bilişsel süreçlerin şiir yorumundaki rolünü daha iyi anlamış olacağız.

\section{2. Şair Hakkında}

Lina Kohen Albukrek 1898 yılında Çorlu'da dünyaya gelmiş bir Sefarad şairidir. İlk gittiği okulda İspanyolca, Fransızca, şiir, matematik, el işi ve müzik dersleri almış, daha sonra Çorlu Rum okuluna devam etmiş ve mandolin dersi almıştır. 1918 yılında ailesi ile birlikte İstanbul'a gelerek Sirkeci'ye yerleşmiştir. 1923 yılında Galata'ya taşınmış ve 1926'da Kalef Albukrek ile evlenmiş ve 1927 yılında birinci kızı Sara ve 1936 yılında ikinci kızı Beki dünyaya gelmiştir. İspanyolca, Türkçe, Fransızca, Almanca ve İbranice bilmektedir. 21 Kasım 1985 yılında vefat etmiştir. ${ }^{1}$

\section{3. Şiir ve Hanuka Bayramı}

İnceleyeceğimiz şiir ve kafiye düzeni aşağıdadır² (şiirin çevirisi ektedir):

\section{Hanuka}

Mos viene la fiesta de la Hanukia a

A todos mozos inçe de alegria a

La mujer nunka manka de su taria a

Porke a eya enkombe Hanukia a

Los Hazmonayim en este luzio dia a

Mostraron sus tan grande baragania a

I siempre de eyos mos akodraremos $b$

I al Dio grande siempre bendizeremos $b$

Ke plazer ya es para las kreaturas C

Kuando empesan a resivir dulsurias c

Los tan ermozos cugetikos del padre d

Kon las tan luzias karesas de la madre d

$a$
$a$
$b$
$b$

a


Nunka no tengamos mal ni hazinura $\mathrm{f}$

Ke no mos de nunka ningun'amargura $\quad f$

\section{Hanuka}

Bize geliyor Hanukiya bayramı,

Biz hepimiz doluyoruz neşeyle,

Kadın ev işini eksiksiz yapar,

Çünkü Hanukiya ona coşku verir.

Haşmonaylar bu 1şıltılı günde

Gösterdiler çok büyük başarılarını.

Ayrıca her zaman onları hatırlayacağız

Ve ulu Tanrı'yı her zaman kutsayacağız.

Ne neşedir çocuklar için

Tatlıları almaya başladıklarında

Babanın çok güzel kucaklamaları

Annenin 1şıltılı sarılmaları ile birlikte.

Tanrı bizi çok büyük bir acıdan kurtardı,

O her zaman bizim ulu koruyucumuz olsun,

Hiçbir zaman ne acı çekelim ne de hüzünlenelim,

Hiçbir zaman hiçbir tatsızlık uğramasın bize.

Çeviren Derya Agiş

Bu şiirde bir Musevi bayramı olan Hanuka Bayramı'nın kutlanılışı ve bunun yarattığı sevinç anlatılmıştır. Dolayısıyla Hanuka bayramının tanımlamamız yerinde olacaktır. Hanuka Bayramı, Kislev ayının 25'inci günü kutlanır ve sekiz gün sürer; bu bayram, Haşmonaylar' n $^{3}$ Suriye Kralı Antiohus Epifanes'e karşı zaferini hatırlatır (İbrani Din Bilgisi, 1992: 46). Makkabi İsyanı olarak bilinen bu olay, Musevilerin inançları uğruna tarihte ilk defa savaşıp başarı kazanmalarının öyküsüdür; sekiz gece mumlar yakıldığından Işıklar Bayramı olarak bilinir (Alalu, Arditi, Asayas, Basmacı, Ender, Haleva, Maya, Pardo ve Yanarocak, 2001: 59). Hanuka Bayramı'nda Museviler fakirlere ve cemaatteki muhtaçlara

\footnotetext{
${ }^{3}$ 1. yüzyılda yaşamış olan Yahudi tarihçi Flavius Josephus'un The Antiquities of the Jews adlı eserinde belirttiğine göre dedeleri Hasmoneus, yani Haşmon olan Yahudiler Haşmonay'lar ya da İbranice olarak Haşmonayim olarak bilinir ve Makkabiler Haşmonay soyundan gelir (Hasmonean Dynasty, 2017). "Helenleştirme politikasına karşı Makkabi lakabıyla anılan" Haşmonay soyundan gelen bir aile Yahudiler'in direnişe başlamasını sağlar (MÖ 167-164), direniş sonucu belirli bir toprak parçası Haşmonay hânedanının yönetimine geçer ve sonra bu topraklar yarı bağımsız krallık olur (MÖ 143-63; I ve II. Makkabiler) (Gürkan, 2013: 190-191).
} 
yardım ederler, çocuklar anne ve babalarına hediye aldıkları gibi kendi aralarında da hediyeleşirler (Alalu ve arkadaşları, 2001: 61). Hanukiya ise sinagog ve evlerde sekiz gece boyunca yakılan dokuz kollu şamdanın adıdır (Alalu ve arkadaşları, 2001: 62). Mumlar yakılırken ilk gece yakılacak mum, Hanukiya'nın sağ başındaki yerine konur, ikinci geceden itibaren sola doğru birer mum eklenir, yakış sırası soldan sağa doğrudur; Hanukiya üzerinde farklı konumdaki mum "Şamaş" olup diğer mumların yakımında kullanılır ve her gece refakat mumu olarak yanık tutulur; bu mumlardan birincisi Yaratılışta Tanrı'nın 1şık olsun emrini, ikincisi Tora'nın ilahi 1şığını, üçüncüsü adaleti, dördüncüsü merhameti, beşincisi kutsallığı, altıncısı sevgiyi, yedincisi sabrı, sekizincisi de cesareti simgeler (Alalu ve arkadaşları 2001: 63).

Hanukiya yakan kişi ilk gece mumları yakmadan önce üç dua okur, diğer gecelerde bu duaların sadece ikisi okunur. İlk gece okunan üçüncü dua Tanrı'ya şükretmek içindir, çünkü bayram her yıl engelsiz kutlanabilmektedir (Alalu ve arkadaşları 2001: 64).

Bu bilgilerden sonra şiirin bilişsel şiirbilimsel yorumuna geçebiliriz.

\section{4. "Hanuka" Şiirinde Silinmeler ve Çoğaltmalar}

$\mathrm{Bu}$ şiirde madde isimlerine, isimlerde mecazi anlam yaratacak ya da onları kişileştirecek bazı özellikler eklenmiştir. Şimdi bunları inceleyelim: "la fiesta de Hanukia", "Hanukiya bayramı" aslında [-CANLI, -İNSANİ] bir kavramken, "venir" (gelmek) fiilinin konumunda kullanılarak kişileştirilmiş ve özellikleri [+CANLI, +İNSANİ] hâlini almıştır. Burada bahsedilen bayrama ilişkin özellik çoğaltması yapılmıştır. Ayrıca Hanuka kelimesinin yerine Hanukiya, yani şamdanın ismi verilerek okuyucunun zihninde bu bayramda yapılanların daha sembolik bir şekilde temsil edilmesi sağlanmıştır. Takibi satırlardaki inçir (doldurmak) ve enkomber (coşturmak) fiilleri de özne konumundaki Hanukiya bayramının kişileşmesini ve canlı bir varlık gibi etkili olmasını sağlamıştır.

İkinci kıtada Hanuka bayramı bir "luzio dia" ("aydınlık gün”) olarak tasvir edilmiştir, çünkü bu bayram boyunca sekiz gün süreyle evlerde mum yakılmaktadır. Bu güne [KARANLIK, +AYDINLIK] özellikleri verilmiştir. Gecenin karanlık geçmesinin bile anlam silinmesi yoluyla aydınlık olarak okuyucu zihninde hayal edilmesi düşünülmüştür. "Dulsurias", yani tatlılar çocukların mutluluk kaynağıdır bu günde. "Cugetikos", kucaklamalar babanın sevgi göstermesi, "karesas", sarılmalar ise annenin sevgi göstermesinin tasvirinde kullanılmıştır. "Dulsurias"1n ("tatlılar") [+TATLI, +MUTLULUK VERİCİ] özellikleri kullanılmış, şişmanlatıcı özellikleri şiirdeki kelimenin özelliklerinden çıkartılmış, yani silinmiştir. Kucaklamalar [+BABAYA AİT, +ÇOK GÜZEL], sarılmalar ise [+ANNEYE AİT, +ÇOK IŞILTILI] özellikleri eklenerek, yani anlam çoğaltması yapılarak üçüncü kıtada kullanılmıştır. 
Son kitada ise Tanrı'ya, "el Dio"ya [+ULU, +SONSUZ VAR OLAN, +KURTARICI, +ACIYI YOK EDEN] özellikleri eklenerek Tanrı yüceltilmiştir.

Şiirde Hanuka Bayramı́nın çağrıştırdığı ögeler, bu tür anlam silinmesi veya çoğaltması yoluyla insan zihninde daha iyi bir şekilde tasvir edilebilir bir hâl almıştır.

\section{Yersel ve Zamansal Yakınlık}

Hanuka şiirindeki zamansal devamlılığı incelendiğinde Hanuka Bayramı'nın eskiden beri kutlandığı ve gelecekte de kutlanacağı fark edilir. Şiirin ilk kıtasında şimdiki zaman kullanılarak bu bayramın her yıl kutlanıldığı gibi yazıldığı yılda da kutlanıldığ hatırlatılmıştır; şiirin Türkçeye çevirisinde de bunu gözlemleyebiliriz:

"Bize geliyor Hanukiya bayramı,

Biz hepimiz doluyoruz neşeyle,

Kadın ev işini eksiksiz yapar,

Çünkü Hanukiya ona coşku verir."

Şiirin ikinci kıtasının ilk cümlesinde geçmiş zaman kullanılmıştır, çünkü Hanuka bayramının tarihine değinilmiştir:

“Haşmonaylar bu işıltılı günde

Gösterdiler çok büyük başarılarını"

$\mathrm{Bu}$ cümleyi izleyen cümlede ise gelecek zaman kullanılarak bu bayramı kutlama geleneğinin devam ettirileceği vurgulanmıştır:

"Ayrıca her zaman onları hatırlayacağız

Ve ulu Tanrı'yı her zaman kutsayacağız."

Dolayısıyla mekânsal devamlılı̆̆ı şiirde kullanılan zamanlardan tahmin edebiliriz: bayramın kutlandığı ve kutlanacağı yer Musevi ailelerin evleridir; Hanukiya, Hanuka bayramında Musevi ailelerin evlerinde yakılır. Çocuklar komşularından, akrabalarından şekerler alırlar, anne ve babalarıyla evlerinde kucaklaşırlar. Son dizedeki dilek kipi kullanımı ise şiir öznesinin bu kutlamaların sürmesi ve Tanrı'nın acıları uzak tutması isteğiyle açıklanabilir. Bu zaman kullanımı, tüm dünyada Tanrı'nın Musevileri acılardan uzak tutması dileğini yansıtır. Bu dilek Hanuka zamanı yapılan duaları çağrıştırmaktadır. Bu dileklerin yapıldı̆̆ı son kıtanın çevirisi aşağıdadır:

“Tanrı bizi çok büyük bir acıdan kurtardı,

O her zaman bizim ulu koruyucumuz olsun,

Hiçbir zaman ne acı çekelim ne de hüzünlenelim,

Hiçbir zaman hiçbir tatsızlık uğramasın bize." 


\section{Kavramsal Sinıflandırmalar}

Hanuka başlık olarak, Musevi bayramlarından biri olan Hanuka yani Işıklar Bayramı'nı hatırlatır ve bu başlık, bayramla ilgili kavramların şiirde açıklanacağıyla ilgili bir ipucudur. $\mathrm{Bu}$ durumda, Musevi bayramları üst kategori, Hanuka ise bu üst kategorinin bir alt kategorisidir.

Hanukiya kavramına gelince, bunun üst kategorisi şamdandır. Sadece Hanuka bayramlarında kullanılan Hanukiya, şamdan kelimesinin ve kavramının sözlüksel olarak bir alt kategorisidir. "Hazmonayim", Haşmonaylar Suriye Kralı Antiohus Epifanes'e karşı zafer kazanmışlardır, Museviler bu zaferi daima hatırlayacaklardır. Haşmonaylar'ın üst kategorisi Museviler, Musevi kavimlerdir. Tanrı ise evrenin hâkimidir ve büyüktür, uludur; zaferin kazanılması Tanrı'nın yardımı olmadan imkânsızdır. Bu sebeple, Museviler Tanrı'ya daima ve her zaman şükredeceklerdir. Tanrı üst ve alt kategorisi olmayan bir kavramdır, çünkü tektir. Tektanrıcılığın savunulmasını şiirdeki bu Tanrı övgülerinde görmekteyiz. "Plazer", yani zevk çocukların tatlıyı yerken duydukları hazdır; "dulsurias", yani tatlılar ise bunun bir üst kategorisidir. Şiirde bu ismin şeker, çikolata gibi alt kategorilerine yer verilmemiştir. Sevgi ifade etmek için başvurulan davranışlar arasında ise kucaklamak, okşamak, öpmek ve gülümsemek vardır. Bu durumda, "cugetikos" ("kucaklamalar") ve "karesas" ("sarılmalar") sevgi ifade etmek için kullanılan kavramlarıdır.

Şiirdeki sözlüksel kategorilere de değindikten sonra şiirin çerçevesine bakalım.

\section{7. Şiirin Çerçevesi}

Şiirin çerçevesini bir Hanuka Bayramı'nın kutlanması oluşturuyor. Bu bayramda herkesin neşe dolduğunun, kadının coşkulu olduğunun söylenmesi bayramda yaşanan mutluluğu okuyucuya yansıtmaktadır. Haşmonaylar'ın bu günde güçlerini gösterip zafer kazanmaları bu bayramın kutlanma sebebidir. Şiirde bu da belirtilmiştir. Bu bayramda Museviler bu zafer için Tanrı'ya şükreder, bu bayramda çocuklara şeker verilir, çocuklar babaları ve anneleriyle kucaklaşırlar. Museviler dualarıyla böyle güzel bir bayramın ileride de neşe içinde kutlanmasını dilerler. Bütün bunlar şiirin insan zihninde çizdiği resimdir, buna da şiirsel çerçeve adı verilir.

\section{Ruhsal Alan}

Şiirin ruhsal alanı, bir üst kategoride yer alan bir kavramın mecazi anlamının alt kategorisindeki farklı somut kavramların edebî eserde verilmesiyle ortaya çıkar (Tsur 1992: 238). Hanuka şiirinin ruhsal alanını üst kategorisi Musevi bayramları olan Hanuka oluşturmuştur. Şiirde Hanuka Bayramı bu bayramda kullanılan objeler ile resmedilir. Bu objeler, Hanukiya, tatlılar ve kucaklaşmalardır. Ayrıca "luzio dia" ("1şıltılı gün") sıfat cümlesi 
de Hanuka Bayramı'nı temsil ederek bu ismin bir alt kategorisi olarak dikkat çeker. "Luzias karesas" ("1şıltılı sarılmalar") sıfat cümlesi de bu bayrama özgü bir sevgi ifadesi olarak annenin çocuğuna sarılmasını betimliyor. Bütün kelimeler, okuyucunun ruhunda Hanuka'nın -Işıklar Bayramı- kutlandığı günü hatırlatır: Mumlar yakılır, çocukların tatlı yer ve ebeveynleri ile kucaklaşır.

\section{Semboller, İmalar, Kafiyeler}

$\mathrm{Bu}$ şiirde kullanılan Hanukiya kelimesi, bayram kelimesine eklendiğinde kelimenin şiirdeki sembolik rolü ortaya çıar: babanın kucaklamasının güzel, annenin sarılmasının ise 1şıltılı olması. Bunlar sembolik olarak, ebeveyn sevgisinin kutsallığını, anne sevgisinin ise anne doğuran kişi olduğu için daha kutsal olduğunu ileri sürer. Özellikle son kıtada ima edilen şey, Hanuka Bayramı́nın kötü ve acı dolu bir savaştan sonra mutlu bir zaferin kutlaması oluşudur ve buna şükretmek için dua edilmesi gerektiğidir.

Kafiyelere gelince, ilk kıtanın son kelimelerin hepsi aynı hece ile bitmektedir, bu kıtanın kafiye düzeni a a a şeklindedir. Bu düzen Hanuka bayramının gelişinin neşeli bir olay olduğunu vurgular. İkinci kıtanın ilk iki satırının yine a a kafiye düzeni ile yazılması Hanuka'nın gelişinin neşesinin bütün şiire hâkim olduğunu bu tür bir kafiye tekrarı ile gösterir. Aynı kıtanın diğer iki satırının "i" ("ve") bağlacıyla başlaması ve b b kafiyesiyle bitmesi bu kafiyelerin gelecek zaman kullanımından kaynaklanması ile birlikle şairin ve şair biz öznesini kullandığı için tüm Museviler'in, Haşmonaylar'ın zaferini daima kutlama isteğini gösterir.

Üçüncü kıtanın ilk iki satırının kafiye düzeni c c olduğundan bu kıtada askerlerden, savaşın detaylarından değil de, başkalarından bahsedildiğini anlarız, burada çocuklardan ve anne-babalarıyla bayramlaşmalarından söz edilir. Bu kıtanın son iki satırının d d kafiye düzeni ile bitişi ise anne ve baba sevgisinin bir bütün oluşturduğunu ve ailenin kutsal bir kurum olduğunu belirtir.

Son kıtanın ilk satırları e e kafiye düzeniyle başlar ki burada da artık çocuklardan değil, Tanrı'dan bahsedilmektedir. "Salvador" ("kurtarıc1") ile "dolor" ("acı") kelimeleri arasındaki bu kafiye acılardan kurtaran kişinin Tanrı olduğunu gösterir. En son iki satırdaki f f kafiye düzenindeki iki kelime "hazinura" ve "amargura" eş anlamlıdır. İkisi de acı, hüzün, üzgünlük, dert, tatsızlık anlamına gelir. Şair, bu duyguyu bir daha Museviler'in tatmasını istememektedir. Bu kısım, Tanrı'ya putperestlere, çoktanrılı bir dine inananlara karşı kazanılan bir zafer için şükretmenin gerekliliğini anlatır.

Şiirin kafiye uyumu ve seçilen kavramlar birbirleriyle son derece uyumludurlar ve şiire neşe duygusu hâkim olduğundan enerjisi yüksektir. 


\section{Sonuç}

Lina Kohen Albukrek'in Hanuka şiiri, bilişsel oyunlarla okuyucusunda neşe uyandırmakta ve okuyucu, şiirdeki dilsel oyunlara bağlı kalarak hayal gücüyle resmettiği Hanuka Bayramı'nı gerçek bir neşe ile yaşamaktadır. Bu neşe duygusu ve şiirde anlatılanların altında yatan bilişsel faktörler Brandt ve Brandt (2005)'ın da savunduğu gibi gramerde ve telaffuzda, yazının anlambilimsel içeriğinde, kafiyelerde gördüğümüz sesletimsel faktörlere ve eserde kullanılan sembollerin ortaya çıkarttığı, okuyucunun hayalinde canlandırabildiği eserde betimlenen estetik, yani sanatsal konuma bağlıdır. Tsur, bilişsel şiirbilim teorisiyle bilişsel bilimler, edebiyat ve dilbilim alanlarına reddedilemeyecek bir katkıda bulunmaktadır.

Gelecekte diğer Sefarad şiirlerine bilişsel şiirbilimsel açıklamalar getirilebileceği gibi bu şiirlerdeki sapmalar ve eksiltili yapıların anlambilimsel özellikleri üzerine çeşitli çalışmalar yapilabilir.

\section{Kaynakça}

Albukrek-Kohen, Lina (1985). 87 Anios lo Ke Tengo. İstanbul: Gözlem.

Alalu, Suzan, Arditi, Klara, Asayas, Eda, Basmacı, Teri, Ender, Fani, Haleva, Beki, Maya, Dalya, Pardo, Ninet veYanarocak, Sara (2001). Yahudilikte Kavram ve Değerler. Yusuf Altıntaş. Hazırlayan. İstanbul: Gözlem.

Brandt, Line ve Brandt, Per Aage (2005). "Cognitive Poetics and Imagery." European Journal of English Studies. Cilt 9, No. 2 2005, sayfalar 117 - 130.

Gürkan, Salime Leyla (2013). "Yahudilik." Türkiye Diyanet Vakfı İslam Ansiklopedisi. Cilt 43, sayfalar 187-197. Web: http://www.islamansiklopedisi.info/dia/pdf/c43/c430113.pdf, erişim tarihi: 24/01/2017.

Hasmonean Dynasty (2017). Encyclopædia Britannica. Web: http://academic.eb.com/levels/collegiate/article/39464, erişim tarihi: 24/01/2017.

İbrani Din Bilgisi (1992). İstanbul. Türkiye Hahambaşılığı'nın ön sözüyle yayımlanmıştır. Ratey, John ( 2001). A User's Guide to the Brain. Londra: Abacus.

Rizzolatti, Giacomo ve Corrado Sinigaglia (2008). Çevirmen: Frances Anderson. Mirrors in the brain: how our minds share actions and emotions. Oxford: Oxford University Press.

Tsur, Reuven (1992). Toward A Theory of Cognitive Poetics. Amsterdam, Londra, New York, Tokyo: North Holland.

Tsur, Reuven (2002). Aspects of Cognitive Poetics. Semino, Elena and Calpeper, Jonathan, Editörler. Cognitive Stylistics - Language and Cognition in Text Analysis, sayfalar 279-318. Amsterdam/Philadelphia: John Benjamins Publishing Company. 